\title{
Business Models to Exploit Possibilities of E-mobility: An Electricity Distribution System Operator Perspective
}

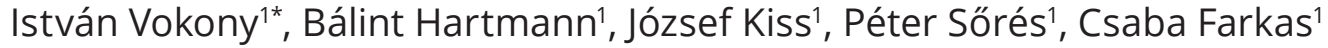 \\ ${ }^{1}$ Department of Electric Power Engineering, Faculty of Electrical Engineering and Informatics, \\ Budapest University of Technology and Economics, H-1111 Budapest, Egry József utca 18., Hungary \\ * Corresponding author, e-mail: vokony.istvan@vet.bme.hu
}

Received: 27 August 2018, Accepted: 23 November 2018, Published online: 26 February 2019

\begin{abstract}
E-mobility is a fast-developing field of electrical industry not only in in Hungary but in Europe and worldwide as well. Besides their environmental, social and economic benefits, electric cars offer further significant possibilities for distribution system operators, for example through the exploitation of controlled charging. This is a hot research topic, but uniform and well-tried solutions are still not available. Actors in electromobility are still forming, thus it is still not known which customer groups might be partners in controlled charging.

Present paper enlists solutions offering more than traditional optimization processes based on solely one objective function. The five business solutions proposed here aim at matching electric cars with the present and future operation of DSOs. Two methods (Vehicle2Home and Night Rider) target individual customers, while the other three proposals (E-pump, plug\&WORK, ENTERPRISeFLEET) are for fleets. A common framework is used to describe these methods here, and both potential customers and the advantages for DSOs are given. Out of the five solutions above, a detailed business model was developed for three concepts, specifying costs and expected incomes. Avoided costs were identified separately, which include all expenses that might be qualitatively or quantitatively influenced by charging of electric cars or controlled charging.
\end{abstract}

Keywords

distribution system operator, business model, e-mobility, charging infrastructure, avoided cost

\section{Introduction}

The 2014/94/EU directive on the deployment of alternative fuels (electricity, compressed/liquified natural or petroleum gases, hydrogen) infrastructure is an integral part of the continuous legislative procedure of the European Union. Although according to Domanovszky (2014) gas propulsion could be a cheaper solution to clean transportation e-mobility takes most of the research, public and regulatory attention. The Hungarian Electric Energy Act (Act LXXXVI of 2007 on Electric Energy) and the corresponding Implementing Decree (273/2007 (X. 19.) Government Decree) defines "charging of electric cars", since 2015. According to this definition, charging can be of the following types:

1. charging at (public) charging stations,

2. charging at a private charging station on a directly measured line,

3. non-profit charging at privately owned electricity meters, in the case of residential consumers and non-residential consumers.
It is an important part in the legislation that profit-oriented charging is only allowed for charging station operators with a valid license. Along with the regulatory hurdles, the adoption of electric cars is also hindered by the lack of proper charging infrastructure, yet the situation is complex and ambiguous (Duran, 2015; Hall and Lutsey, 2017; Salah and Kama, 2016; Verbruggen, 2016).

However, Hungarian legislation does not answer a number of questions (similarly significant regulatory gaps can be identified in other countries as well, such as in China as Yang et al. (2018) showed). Relevant laws only determine the basic framework of the electric charging service model by defining the limit between electricity trading and electric charging service. The most crucial task now is to define the whole charging service model together with new roles (for example clearing house, aggregator, storage), and to pair up tasks with roles. The charging service itself needs to be clarified, as there are two basic approaches to this according 
to the fundamental structure. In one case, the focus is on selling the product (but not as electricity retailing) - in this case, charging of electric cars are defined as "filling" an alternative fuel for vehicles (for example subject to excise duty). In the other case, charging is defined as a pure service, for which a completely new regulation can be set up.

Based on the knowledge of market and regulatory circumstances, possible business models for electricity distribution system operators (DSOs) are suggested and analyzed here. A pre-requisite for such a task is to define and analyze the present and future role of the DSO, which is discussed in Section 2. Section 3 focuses on the methods applied in this study to ensure that the elaboration and results of the different business models could be compared to one another. Section 4 describes the suggested models in detail, together with the results of their analysis and a suggestion for market possibilities. The paper is concluded with the summary of the results.

\section{Possible models - DSO role}

Owing to the probable significant market penetration of electric vehicles in the near future, DSOs must prepare for the management of adverse network effects arising due to charging (Ramadan et al., 2017). Furthermore, they must gather the possible technical and non-technical solutions for the charging of electric cars that facilitate the management of these network effects and thus are valuable for the DSO. Therefore, it is of primary importance for the DSOs to have a suitable model for electric car charging. This new model does not necessarily equals a new business potential, it must simply be introduced in order to ensure the further operation of the network (Rossignoli and Lionzo, 2018).

This research focused on models based on regulated charging; however, although their necessity is widely acknowledged, no specific business model has been prepared for these models. This problem is mentioned for example by Niesten and Alkemade (2016). Moreover, several perspective business models, such as Better Place (Niesten and Alkemade, 2016) have gone bankrupt. Therefore, this study has applied a wider scope, examining further possibilities in connection with the charging of electric cars.

It is self-evident that DSOs operating low and middle voltage networks will play a decisive "enabler" role in the spreading of electric cars. Speaking of value creation, however, it is not so trivial what possibilities DSOs have besides guaranteeing stable grid connection. Literary sources agree that partly owing to regulatory limitations, DSOs are unable to address the new challenges posed by the spread of electric cars alone. Therefore, a close cooperation with other market players (such as car manufacturers, local governments) is needed and probably new players must also enter the e-mobility value chain (for example aggregators). As Kieckhäfer et al. (2017) highlights, manufacturers' decisions have a strong influence on the development of electric vehicles' market, thus have a competitive advantage in shaping the future of e-mobility.

At many places, it is still debated whether DSOs should take part in the innovation or the regulator will order it to accept new technology, and thus the DSO would become a passive player (Melton, 2016). However, all relevant studies agree that for the time being it is much simpler if the DSO plays an active role in setting up the new infrastructure, as the effective management of this rather capital-intensive investment needs to rely on the experience of DSOs.

In the past few years, several standards (Table 1) have appeared in connection with the charging of electric cars. According to the most widespread regulation in Europe, the group of standards IEC 61851 describes the requirements for wired charging. The standard defines four ways of charging:

- Mode 1 - Slow AC charging from standard power connector, maximum current is $16 \mathrm{~A}$ per phase.

- Mode 2 - Slow AC charging from standard power connector, the installation requires earth leakage and circuit breaker protection. Through an intermediate electronic device with pilot control function, basic communication between the controller and the vehicle is possible.

Table 1 The most important standards for charging electric cars, categorized according to field of applicability (based on Salah and Kama, 2016; Bakker et al., 2015)

\begin{tabular}{ll}
\hline Measure & \multicolumn{1}{c}{ Standards } \\
\hline Connector & SAE J1772, IEC 62196-1, IEC 62196-2, \\
& IEC 62196-3, GBT20234-2, GBT20234-3 \\
Safety & IEC 60529, IEC 60364-7-722, ISO 6469-3, \\
& ISO 17409, SAE J1766, SAE J2344, SAE J2929, \\
& SAE J2578, SAE J2464, SAE J2380 \\
Communication & SAE J2931/1, SAE J2931/2, SAE J2931/3, SAE \\
& J2931/4, SAE J2931/5, SAE J2931/6, SAE J2931/7, \\
& SAE J2847/1, SAE J2847/2, SAE J2847/3, SAE \\
& J2847/4, SAE J2847/5, SAE J2847/6, ISO/IEC \\
& 15118, IEC 61851-24, IEC 61850, IEEE 80211P, \\
& GBT 27930 \\
& SAE J2836/1, SAE J2836/2, SAE J2836/3, \\
Tharging & SAE J2836/4, SAE J2836/5, SAE J2836/6, \\
& IEC 61851-1, IEC 61851-21, IEC 61851-22, IEC \\
& 61851-23, GBT20234-1, IEEE P2030.1, \\
& IEEE P2030.2, IEEE P2030.3, IEEE P1547/1, \\
& IEEE P1547/2, IEEE P1547/3, IEE P1901.2 \\
Interoperability & SAE J2953/1, SAE J2953/2 \\
\hline &
\end{tabular}


- Mode 3 - Slow or semi-fast AC charging from a special connector for EVs, with integrated pilot control functions and protections.

- Mode 4 - Fast DC charging through a fixed external charger, with a specific connector for EVs.

It is important to highlight that Mode 1 charging does not establish communication between the charging point and the vehicle possible. In Modes 2 and 3, low level communication between the charger and the vehicle is made possible by the controlling pilot signal. In the case of fast charging according to Mode 4, there is a defined communication transmission in order to manage the charging of the battery (Hu et al., 2016).

Concerning special connectors, standard IEC 62196 defines three types (Type 1-3). In essence, Type 1 connector equals connector defined in standard SAE J1772, while Type 2 equals VDE-AR-E 2623-2-2 connector. For the sake of completeness, it must be mentioned that in the US standard SAE J1772 describes regulation for charging. In a similar manner to the European norms, this standard differentiates categories: 3 levels are defined for AC and DC charging, respectively (Levels 1-3). AC Level 1 charging roughly equals slow home charging, while AC Level 2 solution might equal public or business applications. Level 3 charging is fast charging, which can be AC or DC as well. The three different power levels of DC fast chargers can be applied to public fast chargers (Hu et al., 2016).

Controlled charging can only be achieved if there is some form of communication between the charger and the vehicle. Additionally, the existence of another communication channel is also indispensable: the one between the charger and the control unit that regulates charging. Consequently, from the point of view of this study Mode 1 and 2 charging are of little relevance. The possibility of controlled charging is also questionable in the case of fast chargers, as users wish to charge their car as fast as possible, without any fluctuations in power or any delay.

\subsection{DSO roles}

Besides expanding the charging system, DSOs can play several other roles, which are listed below. A DSO can be either a supporter or an active market player, as long as local legislation on energy makes it possible. It is important to note, however, that regulation can place severe obstacles in the way of value creation, as shown by de Heer and Allan (2015): DSOs can
- ensure flexibility for reserve market players, in the case of their own EV charging points (Rezania and Prüggler, 2012);

- play a role in the recycling of used batteries (second-life usage). Amortized vehicle batteries might be used in the network, DSOs can use them for bottleneck management and for other energy trade and balancing applications (de Heer and Allan, 2015; Rezania and Prüggler, 2012; ).

\subsection{Use cases}

In the followings the most common and relevant use-cases are summarized from DSO point of view. The emphasis was on DSO's today core and non-core possibilities.

- Vehicle-to-grid (V2G), Vehicle-to-Home (V2H): The charging process of electric cars can be controlled by the increasing or decreasing of the charging power, or even by turning the direction of charging backwards. During this regulation it is advantageous if the batteries of cars connected to the system are not fully charged and are not fully discharged either, as this is required for a sizeable power regulation margin. The entity responsible for charging should create incentives for customers to achieve this state of charge that should also support both the interests of energy trading and of the network operator according to Rezania and Prüggler (2012) and Kaufmann (2017). While Kaufmann (2017) claims that the V2G should be implemented by a separate IT company, de Heer and Allan (2015) argues that this should be achieved by the DSO. Concerning V2G solutions, Kaufmann (2017) also gives the following statements:

- As for V2G, the profit provided by only one car is very small and the construction of an appropriate charging station is expensive, customers joining the V2G system need incentives.

- VG2 implementation is profitable in the case of low power AC chargers that are capable of ensuring the communication needed for bidirectional charge flow (that is the CHAdeMO standard is not sufficient).

- A very large number of users is needed, as one vehicle has very little V2G potential.

- It is also possible to include vehicle fleets, for example buses into such a system. This is underlined by Melton (2016), as well. 
- Car sharing: Besides regulated charging, public electric car sharing systems and car rentals can be set up (Kaufmann, 2017).

- Battery leasing: Batteries might be owned by the organization in charge of $\mathrm{V} 2 \mathrm{G}$ instead of the car owner, and it is thus leased to the owner. This is a problematic solution as it largely depends on how much car manufacturers make their own data public (de Heer and Allan, 2015). However, if battery leasing gets widespread, energy providers might offer complex packages for which DSOs must offer incentives.

- Supporting charging station building: When the system is installed, the charging station should be handed over to the user as part of the package (de Heer and Allan, 2015).

- Roaming: Uniform invoicing system should be set up, that is invoicing should be independent of the place of charging (de Heer and Allan, 2015).

- Battery storages should be set up at charging stations (Hall and Lutsey, 2017).

Current regulation often excludes the possibilities of the DSO to include the emerging available new technologies into their network and business model. The limitations of the present regulation have been acknowledged by leading regulatory authorities, and thus they are working on the creation of supportive legislation (Hay and Macwhinnie, 2015; Verbruggen, 2016).

In any case, as the spreading of electrical vehicles is a hot topic, more and more versatile new roles emerge in the market. On the one hand, it is a positive development that the load of this cost-intensive process is to be shared owing to innovation in business and technology. On the other hand, this process makes it increasingly difficult to define and compare the possibilities and limitations of the present market players. The different business models are to be compared here with the help of business model canvas.

\section{Methodology}

Business models can be implemented with various methods and in various sizes. Business model canvas, a method coming from the world of start-up businesses, is an ideal method for setting up plans even for less experienced people. (França et al., 2017)

Yves Pigneur and Alex Osterwalder started to look for the main elements that are needed for an organization to make decisions in the course of setting up its business model. They analyzed the available literature, the prototypical and recurring models, and the elements were given for a stress test to business executives and experienced entrepreneurs. The emerging scheme was a business model made up of nine building blocks, which was later developed into the Business Model Canvas in a $\mathrm{PhD}$ thesis (Osterwalder, 2004). Ever since, the model has been used by millions: beginning from Fortune 500, through start-up businesses to community enterprises value this approach, which is also used by local governments and state-owned companies.

The building blocks of a stable enterprise are summarized on a comprehensive single sheet. The first block is the group of customers - that is all those to whom the company offers services or sells something. The second block is the value propositions: everything that constitutes the essence and the individuality of the service or the product. The third block is constituted by the channels through which the value propositions reach customer groups. This serves as the basis for classic PR and marketing communication. Customer relationships are placed above this block: these include contacts with customers, feedback, collection of ideas, customer satisfaction. Sales activities and quality assurance processes also belong here. If this functions well, income is produced here, which provides one side of cash flow.

In order that all this can be undertaken and run, key resources are needed, which might be of several types: human, mental and financial resources or assets (for example web page, social media platforms, brand name). With the help of these resources key procedures can be achieved, which constitute key aspects for executing the value propositions. This is complemented by key partners, that is all those whom the entrepreneur pays - inner or outer partners, subcontractors, service providers from whom key resources are obtained. These three building blocks make up the costs, the other side of cash flow model.

Business Model Canvas is useful for both starting and operating enterprises, and it can also be used if there is only a new idea to be implemented. This method gives feedback about the feasibility of the idea and might offer solutions for amending hindrances. It is important to note that this general model can be customized to special company needs and environments. This research identified those elements that cannot be regarded as classic income while they influence the total balance: this is the category of avoided costs. These include all expenses that might be qualitatively or quantitatively influenced by charging of electric cars or charge control. As a result of these two processes, the flow 
characteristics of the electric power system (primarily the distribution network) change in certain periods. This induces technical effects (such as a change in network loss, the fluctuation of voltage) and might have measurable economic effects (for example income from network usage fee, shifting peak periods). The quantification of the effects of avoided costs and the exhaustive list of such items strongly depends on the exact location and the given power plant, and thus needs further research. As this topic falls outside the main scope of this study, here we only refer to these expenses with the umbrella term "avoided costs".

\section{Proposed concepts}

This section describes concepts which make it possible to create and operate mass control of EV charging. The solutions given here all go beyond the widely discussed optimization processes based on a single target function and try to match up the system of electric cars with the present and future role of the DSO. The five methods below include some solutions offered for individual and fleet customers, methods for selling energy and infrastructure as well.

\subsection{V2H (Vehicle-to-Home)}

Vehicle-to-Home is a solution for private households: the electric car is connected to the electric network of the house or garage, and it functions as an energy storage device - it can take up energy from the system and can also give energy to the system. That is the target community of V2H is made up of people who own a house or garage where a charging point can be constructed. If these charging points are wide-spread enough, it is possible to aggregate individual $\mathrm{V} 2 \mathrm{H}$ customers into a larger controllable unit, which - if regulated properly - may be included in legislative roles that are favorable for the regulatory authority as well (this is V2G solution).

However, the group of potential customers now is rather small, as electric cars are very expensive, but as Simha (2016) highlights, other vehicles, such as e-bikes shall be considered in decarbonizing urban transportation. Nevertheless, now only wealthy and environmentally conscious people can afford buying e-cars. But, this fact is also an advantage, as the target population lives densily in specific areas, which makes deploying charging regulation easier. If the owner of the vehicle wishes to exploit all the possibilities that a V2H solution can offer, the electric car will only be used rarely, and it will only function as a secondary car in the family.

Although V2H solution can be applied in all circumstances, it can be best exploited if the home also utilizes renewable energy sources. This further supports the fact that this technology targets the wealthy population with private detached or semi-detached houses.

From a DSO perspective, V2H has several advantages and some disadvantages. It is favorable that if the DSO takes part in the construction of private charging points, it will be entitled to ask for a role in controlling the charging process of the car. Thus, it may regulate the residents' energy consumption depending on network load: in the case of high network load homes included in V2H might be switched off-grid - that is at such times consumers get energy from their electric cars. Consequently, a strong potential of $\mathrm{V} 2 \mathrm{H}$ solution is that it makes demand side management possible because of regulated charging, which is effectively alleviates DSO grid constraints as Ramadan (2018) showed.

Also, if the DSO does not influence charging directly with a control signal and only uses indirect incentives, it might also be a favorable solution. In this case, for homes with $\mathrm{V} 2 \mathrm{H}$ potential the best solution is to charge their car when the price of electricity is lower and use this electricity from the battery of the car during peak hours. For the DSO it means that peak hour loads are decreased, and cars are mainly charged during off-peak hours.

On the other hand, it is a serious disadvantage of $\mathrm{V} 2 \mathrm{H}$ solution that users get the capability to autonomously switch to off-grid mode for shorter or longer periods. As they would use the public network neither for consumption nor production, the DSO loses revenue from system usage tariffs. This can be avoided by proper, incentivizing tariffs.

\subsection{Night Rider}

The Night Rider solution is based on the existing multi-tariff price schemes of the suppliers: customers can charge their vehicles at lower prices in off-peak hours. Thus, consumers are incentivized to offer their vehicles for mass regulation. There are two versions of Night Rider solution:

1. only pricing is the influencing factor, that is customers can choose the time of charging;

2. charging is fully controlled, similarly to the present ripple control or radio ripple control systems applied today.

The target group of this approach consists of individual consumers who own electric cars or willing to buy one in the near future. Based on international experience, these customers typically belong to the upper segment of society, are middle-aged and live in cities or the urban area. They 
also have home charging facilities, typically in their private garages, and in many cases operate a household-scale solar photovoltaic plant. (Aliasghari et al., 2018.)

The most important value propositions offered by Night Rider solutions for the DSO are that it makes real mass regulation possible and it seems to be the cheapest solution. The regulation of consumer appliances with known power needs at known consumer points can serve as the basis of a well-predictable energy management system. Another significant advantage for the DSO is that this new product is very similar to the pricing system and regulatory system known and used by a wide range of customers at present. Positive customer experiences attached to off-peak or "night electricity" tariff make it possible to sell them a similar product more easily. Depending on the complexity of the new charging management/control architecture, a smaller or bigger part of the system is already in operation and no significant new connection options or devices are needed to be installed on the existing grid. As this solution is based on offering better and incentivizing tariffs to the consumers, it allows for a great flexibility of the DSO: the price scheme can be modified flexibly.

\subsection{E-pump}

The target customer group in this case are gas station operators. In the current transport infrastructure system, filling stations and complex rest areas play a key role in long-distance transportation. This fuel distribution network, however, is developing dynamically, partly as a reaction to the challenge posed by alternative fuels as e-mobility advances.

Gas stations typically react to these challenges by focusing on high-standard services. Thus, they aim to keep the customer at the stop with additional services (restaurant, shop, accommodation) even if the primary service (refueling) does not take more than five minutes.

The time required for charging an electric car supports the reconstruction of filling stations in this direction. At the same time, the present competitive advantage of companies dealing with fossil fuels will diminish on the long run. New chains may appear on the market, which may even be the subsidiaries of the power market players.

The mobility need of customers at filling stations is rather versatile now. Some want to finish refueling as fast as possible and do the filling themselves. Others spend much more time at the stations. There are normal and premium fuels, filling stations issue loyalty cards and fuel cards. Even professional drivers have their individual decisions on where they fill up their vehicle, as Kovács and Gubán (2017) underlines.

This complex service portfolio is built on the same, standardized fuel, which is of rather fixed quality and has a relatively fixed price as an excise product. From this respect, the electric refueling can serve real customer needs much more flexibly as it can be easily controlled.

However, electric cars do exhibit various charging needs and abilities (performance, capacity, connector type), and the different charging methods are not fully equivalent for the customer (e.g. battery amortization).

Fast charging will be a basic service in the future. One of the competitive advantages of filling stations will be that they can provide fast charging for long-distance journeys while also ensuring the required service quality (waiting and charging times). The service can be provided cost-effectivly using optimization techniques developed by Farkas and Telek (2018).

However, customers do not always require fast charging, moreover, it is rather inconvenient for them to park their car to another parking place just as charging has finished. Thus, flexibility in charging modes is the key in keeping and enlarging the customer group of a station.

For medium range, e-mobility will be a factor for the transport of goods as well, for example plug-in hybrid powertrains may become competitive by their efficiency, or if zero emission zones appear and become widespread. In road freight transport drivers must schedule long compulsory rest periods. Charging needs can also be scheduled for these 8-11-hour-long rest periods, which is a competitive advantage for the flexible management and regulation of e-charging.

The satisfaction of significant capacity needs arising from e-mobility is a great challenge for DSOs. However, serving business customers may be profitable if charging regulation is supported. The most important value in this case is making concentrated demand flexible. As filling stations wish to become general service providers, if they can sell profitable retail services, they will cooperate in the process with incentive tariffs or even regulated charging. DSOs can offer individual flexible tariffs for smart charging, because they have direct interest in leveling capacity needs as providers of background infrastructure (Farkas, 2013).

The appearance of electric charging stations significantly changes the infrastructure of filling stations. The operation and maintenance of these new devices requires electrical competences, so the existing servicing 
capacities of DSOs can be very valuable. Further competitive advantages arise from the provision of smart chargers, and from the experience in accounting, data management and measurements.

The supply of high electricity needs of filling stations is an important business value of the e-pump solution. The rising need for electric energy consumption will appear partly at e-charging stations. DSOs can keep and enlarge their share in the growing market if they proactively appear in this segment. Serving large e-mobility service providers may be built on the experiences with small consumers and the operation of own charging stations.

As the use of alternative fuels becomes more widespread and stricter emission standards are introduced, the provision of energy gained from renewables might become a key factor in the field of transportation as well. Aliasghari et al. (2018) showed that by taking part in demand response programs as a flexible load, the EV owners can also profit and the utilization of a parking lot can decrease the cost of renewable source investments by up to $40 \%$.

By serving filling stations, the players of the electric energy market can enter a new market where demand is concentrated and the final customer is acquired by the filling station operator. Market expansion with this B2B approach may be achieved with low risk. Direct customers are financially strong, and they look for a capable power engineering partner for their concentrated developments.

\subsection{Plug\&WORK}

The potential customer group for the plug\&WORK concept is made up of enterprises that operate a fleet of electric vehicles or are planning to set up such a fleet. Furthermore, potential customers use this fleet as a fundamental building block in their business activity. Consequently, vehicles are under high utilization. Potential customers include taxi companies, car sharing system providers, courier services, post offices, food or other commercial truck companies, public transport companies.

For practical reasons, the vehicles of such a fleet are charged at the garages of the company. Owing to extensive usage, vehicles typically arrive at the garage with very low batteries, where batteries must be charged by the time the vehicle is used next. The whole charging infrastructure can be included in a regulated charging scheme.

It is important to note that all customers in this group have well-defined daily schedules, which makes it possible to estimate arriving and departing times and necessary charging power relatively well.
Operating their own charging infrastructure is going to be a new challenge for these companies, since in order to ensure their undisturbed and continuous service, the charging infrastructure must be operated and maintained continuously. As the main activity of these enterprises is not operating electric vehicles, the operation and maintenance of the charging infrastructure can be a separate service or an incentive factor.

Financial motivation can be the most important incentive for joining a regulated charging scheme for this customer group, which is also supported by (Duran, 2015; Hall and Lutsey, 2017; Jones and Lovell, 2015).

The potential customer group of plug\&WORK solutions work according to a well-defined schedule, which is different for each customer. For each fleet user, charging should be provided at a fixed, single location, that is the customer's garage. As the vehicles return with a low battery, charging is almost sure to take place.

Consequently, the charging provider can manage a relatively well-scheduled regulated charging for fleets, in comparison with other solutions described here. Charging is to be achieved any time in the time window in which vehicles are at the garage, that is between the arrival and departure of cars. Another advantage of this setup is that all the charging posts of a garage are at a certain point of common coupling (PCC), with a relatively large capacity that can be regulated.

The operation and maintenance of the charging infrastructure means further business potentials, which does not belong to the competence of the fleet operator. On the one hand, this can be sold as a packaged service to customers; on the other hand, it may be used as an incentive for participation in controlled charging.

\subsection{ENTERPRISeFLEET}

The customers for this solution are owners of electric passenger cars or trucks, or even special machines (for example crane lorry). Besides this, customers are interested in the electric energy field (for example DSO, TSO, energy producer etc.) or in a field which produces or consumes large quantities of energy. Thus, this model makes it possible for the customer to enhance his own profile, to reduce fuel and operating/maintenance costs. Additionally, if the customer has a leasing construction, this agreement might also be modified. Furthermore, an existing business model can also be sold, or an operation service can be offered at places where consumers cannot provide this in the lack of receptivity or capacity. 
The value proposition for DSOs is the same as with plug\&WORK. Moreover, the user and service provider of electromobility might belong to the same entity. For the $\mathrm{DSO}$, the most valuable segment is technology. Due to the regulation of charging, the DSO may check new business opportunities on itself and later turn these profitable. The services connected to regulated charging might include load-shaving, load-shifting, possible arbitrage, secondary spare products etc. if penetration reaches the required level. Moreover, the self-evident risk reducing possibility is also given: testing at the DSOs own garage the requirements for the given service levels can be loosened.

Besides technology-based solutions, the self-enhancement of core business activity is also present. The quantity of sold electric energy can be increased. This is not only a "specious" solution, as DSOs do not sell traditional fuels. Therefore, the dependence on constantly changing market prices and on fuels not belonging to the DSO can be diminished as well.

Economic profit includes the possibility of the revision of existing leasing agreements. Significant tax relief or other additional advantages might be gained if someone enhances the number of electric vehicles in the fleet. It is important to note here that this is not only true for personal cars, but also for small-scale freight-transport and for vehicles supporting technological activities as well.

Finally, the most significant additional value is raising employee awareness, which includes education for environment-consciousness. Also, energy audit surveys identify the use of electric vehicles as a great advantage. Positive effects of awareness raising are unquestionable, and companies can really be proud of this. The credibility of a company is highly enhanced if they use their own products during the environmental education

\section{Results and discussion}

Out of the models elaborated by a detailed analysis not fully presented here, in the present regulatory and market setting, the highest potential for DSOs is offered by the ENTERPRISeFLEET model. Synergies stemming from the presence of energy sources and the infrastructure can be effectively exploited. This model is based on charging of a relatively large fleet of personal cars and technological vehicles used at a given garage and its vicinity. A fleet managed and regulated in a uniform manner as a technological solution can be valuable for a DSO. New business models can be tested without an outside partner, and regulated charging makes it possible to offer specific services, such as load-shaving and -sharing, arbitrage, regulatory reserve allocation.

For DSOs this solution strengthens their main business activity (supplying electric energy) and diminishes the dependence on fuels outside their main scope. Another major advantage of this method is awareness raising, which conveys a positive message about the DSO for both employees and customers. It needs further studies to determine which garages and which part of the vehicle fleet should be worth including in a pilot project for demonstration. Another open question is how create a regionally or nationally aggregated service from decentralized regulated charging which is distributed all over the country.

As the network effects arising from the large-scale spreading of electric vehicles will most probably be a challenge for DSOs, it is a proactive step to examine those technical and other solutions that might help in managing these effects. Thus, it is important for the DSO to prepare a proper model for electric car charging. This model does not necessarily offer new business potentials, but it must be introduced to ensure the further operation of the network.

The following costs arise due to this suggestion:

- Charger - 50-100 pcs/customer - The type and number of chargers to be installed must be determined considering the properties of the fleet. As probably not all vehicles will have to be charged at the same time, the number of necessary charging points is smaller than the total number of vehicles in the fleet.

- Electricity meter - one per garage - a common electricity metering device capable of registering time series of realized consumption must be installed, which allows for regulated charging. (Regulation need not be realized through the meter, though.)

- Network development - is only necessary if the required charging capacity is not available. This process includes capacity increase, change of transformers, installation tasks etc.

- Communication - the new communication infrastructure must allow for two-way communication, which enables measuring and invoicing.

- Operation costs - meter installation and operation, charger installation and operation, entering into a contract, invoicing.

- Accountancy of e-vehicles, purchasing new vehicles.

Possible revenues connected to these suggestions:

- The increase of net promoter score (NPS) due to the rise of marketing value. 
- Income from selling the new service potential.

- Costs of fuel replaced.

- Avoided costs of investments.

\section{Conclusions}

E-mobility is a fast-developing field both at national and international levels. Besides environmental, social and economic profits, electric cars offer significant technical and economic potential for electricity distribution network operators through the opportunities offered by regulated charging. Although this field is in the center of several studies and pilot projects around the world, uniform and finalized solutions have not arisen yet.

This research aimed to suggest profitable business models through the inspection of international practices, including technical solutions, the properties of the

\section{References}

Aliasghari, P., Mohammadi-Ivatloo, B., Alipour, M., Abapour, M., Zare, K. (2018) "Optimal scheduling of plug-in electric vehicles and renewable micro-grid energy and reserve markets considering demand response program", Journal of Cleaner Productions, 186, pp. 293-303.

https://doi.org/10.1016/j.jclepro.2018.03.058

Bakker, S., Leguijt, P., van Lente, H. (2015) "Niche accumulation and standardization - the case of electric vehicle recharging plugs", Journal of Cleaner Production, 94, pp. 155-164.

https://doi.org/10.1016/j.jclepro.2015.01.069

de Heer, H., Allan, P. (2015) "What's driving tomorrow's electricity grid", position paper, DNV GL, Høvik, Norway.

Domanovszky, H. (2014) "Gas propulsion or e-mobility is the solution on the way of clean and carbon free road transportation?", Periodica Polytechnica Transportation Engineering, 42(1), pp. 63-72. https://doi.org/10.3311/PPtr.7254

Duran, R. S. (2015) "Smart charging: steering the charge, driving the change", presented at EURELECTRIC Talking Smart Grids, Brussels, Belgium, Mar. 24, 2015. [online] Available at: https://www3.eurelectric.org/media/171787/sanchez-duran.pdf [Accessed: 10 November 2018]

Farkas, C., Szücs, G., Prikler, L. (2013) "Grid impacts of twin EV fast charging stations placed alongside a motorway" In: 4th International Youth Conference on Energy (IYCE), Siófok, Hungary, pp. 1-6. https://doi.org/10.1109/IYCE.2013.6604144

Farkas, C., Telek, M. (2018) "Capacity Planning of Electric Car Charging Station Based on Discrete Time Observations and MAP(2)/G/c Queue", Periodica Polytechnica Electrical Engineering and Computer Science, 62(3), pp. 82-89. https://doi.org/10.3311/PPee.11841 possible customer group and the methods of customer compensation.

In Hungary, the group of market players for e-mobility is still forming, which will affect the potential customer groups that can be included into regulated charging. Among other things, this study focused on defining potential customer groups based on conclusions drawn from international practices, and on the estimation of regulatory potential for each group.

After the analysis a solution was selected, ENTERPRISeFLEET, which effectively supports the DSOs ambitions concerning e-mobility with respect to the present market and regulation, and the current conditions. Furthermore, this solution offers significant business potential, which exploits the synergy of existing energy sources and infrastructure.

França, C. L., Broman, G., Robèrt, K.-H., Basile, G., Trygg, L. (2017) "An approach to business model innovation and design for strategic sustainable development", Journal of Cleaner Production, 140, pp. $155-166$.

https://doi.org/10.1016/j.jclepro.2016.06.124

Hall, D., Lutsey, N. (2017) "Literature review on power utility best practices regarding electric vehicles", The International Council on Clean Transportation, Washington D.C., USA

Hay, R., Macwhinnie, N. (2015) "Making the electricity system more flexible and delivering the benefits for consumers" [pdf], Ofgem, United Kingdom, Available at: https://www.ofgem.gov. uk/ofgem-publications/96959/flexibilitypositionpaperfinal-pdf [Accessed: 10 November 2018].

Hu, J., Morais, H., Sousa, T., Lind, M. (2016) "Electric vehicle fleet management in smart grids: A review of services, optimization and control aspects", Renewable and Sustainable Energy Reviews, 56, pp. 1207-1226.

https://doi.org/10.1016/j.rser.2015.12.014

Jones, B., Lowell, D. (2015) "Electricity pricing strategies to reduce grid impacts from plug-in electric vehicle charging in New York State", M.J. Bradley \& Associates LLC, Concord, MA, USA, Rep. No. 15-17.

Kaufmann, A. (2017) "Vehicle-to-grid business model - Entering the Swiss energy market", MSc Thesis, University of St. Gallen. Available at: https://smartsolarcharging.eu/wp-content/ uploads/sites/274/2017/08/A.-Kaufmann-Master_Thesis_V2G_ BusinessModel.pdf [Accessed: 11 November 2018]

Kieckhäfer, K., Wachter, K., Spengler, T. S. (2017) "Analyzing manufacturers' impact on green products' market diffusion - the case of electric vehicles", Journal of Cleaner Production, 162, pp. S11-S25. https://doi.org/10.1016/j.jclepro.2016.05.021 
Kovács, G., Gubán, M. (2017) "Planning of Optimal Fuel Supply of International Transport Activity", Periodica Polytechnica Transportation Engineering, 45(4), pp. 186-195. https://doi.org/10.3311/PPtr.10843

Melton, M. (2016) "Utility involvement in electric vehicle charging infrastructure: California at the Vanguard", Center for Strategic \& International Studies, Washington D.C., USA

Niesten, E., Alkemade, F. (2016) "How is value created and captured in smart grids? A review of the literature and an analysis of pilot projects", Renewable and Sustainable Energy Reviews, 53, pp. 629-638. https://doi.org/10.1016/j.rser.2015.08.069

Osterwalder, A. (2004) "The Business Model Ontology - A Proposition in a Design Science Approach", PhD Thesis, l'Université de Lausanne Available at: http://www.hec.unil.ch/aosterwa/PhD/ Osterwalder_ PhD_BM_Ontology.pdf [Accessed: 10 November 2018]

Ramadan, H., Ali, A., Farkas, C. (2018) "Assessment of plug-in electric vehicles charging impacts on residential low voltage distribution grid in Hungary", In: 2018 6th International Istanbul Smart Grids and Cities Congress and Fair (ICSG), Istanbul, Turkey, pp. 105-109. https://doi.org/10.1109/SGCF.2018.8408952

Rezania, R., Prüggler, W. (2012) "Business models for the integration of electric vehicles into the Austrian energy system", In: 2012 9th International Conference on the European Energy Market (EEM), Florence, Italy, pp. 1-8.

https://doi.org/10.1109/EEM.2012.6254771
Rossignoli, F., Lionzo, A. (2018) "Network impact on business models for sustainability: Case study in the energy sector", Journal of Cleaner Production, 182, pp. 694-704. https://doi.org/10.1016/j.jclepro.2018.02.015

Salah, K., Kama, N. (2016) "Unification Requirements of Electric Vehicle Charging Infrastructure", International Journal of Power Electronics and Drive System, 7(1), pp. 246-253. https://doi.org/10.11591/ijpeds.v7.i1.pp246-253

Simha, P. (2016) "Disruptive Innovation on Two Wheels: Chinese Urban Transportation and Electrification of the Humble Bike", Periodica Polytechnica Transportation Engineering, 44(4), pp. 222-227. https://doi.org/10.3311/PPtr.8811

Verbruggen S. (2016) "Germany - The Need for Policy Reforms", Energy Storage Journal. [online] Available at: http://www.energystoragejournal.com/cover-story-germany-the-needfor-policy-reforms/ [Accessed: 14 November 2018]

Yang, T., Long, R, Li, W. (2018) "Suggestion of tax policy promoting the PPP projects of charging infrastructure in China", Journal of Cleaner Production, 174. pp. 133-138.

https://doi.org/10.1016/j.jclepro.2017.10.197 